\title{
Review Article \\ Psychosocial Aspects of Bruxism: The Most Paramount Factor Influencing Teeth Grinding
}

\author{
Mieszko Wieckiewicz, ${ }^{1}$ Anna Paradowska-Stolarz, ${ }^{2}$ and Wlodzimierz Wieckiewicz ${ }^{3}$ \\ ${ }^{1}$ Division of Dental Materials, Faculty of Dentistry, Wroclaw Medical University, 26 Krakowska Street, 50425 Wroclaw, Poland \\ ${ }^{2}$ Department of Maxillofacial Orthopedics and Orthodontics, Faculty of Dentistry, Wroclaw Medical University, \\ 26 Krakowska Street, 50425 Wroclaw, Poland \\ ${ }^{3}$ Department of Prosthetic Dentistry, Faculty of Dentistry, Wroclaw Medical University, 26 Krakowska Street, 50425 Wroclaw, Poland
}

Correspondence should be addressed to Mieszko Wieckiewicz; m.wieckiewicz@onet.pl

Received 5 April 2014; Accepted 23 May 2014; Published 13 July 2014

Academic Editor: Piotr Wiland

Copyright ( 2014 Mieszko Wieckiewicz et al. This is an open access article distributed under the Creative Commons Attribution License, which permits unrestricted use, distribution, and reproduction in any medium, provided the original work is properly cited.

In clinical practice, patients suffering from an occlusal parafunctional activity have increased. It can be observed that a negative influence of environment aggravates patient's health. The aim of this paper is to present the impact of environment and development of human civilization on the prevalence of bruxism and the correlation between them. The authors grasp the most relevant aspects of psychological and anthropological factors changing over time as well as their interactions and describe a relationship between chronic stress and bruxism. Current literature shows how contemporary lifestyle, working environment, diet, and habits influence the patient's psychoemotional situation and the way these factors affect the occluso-muscle condition.

\section{Introduction}

Bruxism is an oral habit consisting of involuntary rhythmic or spasmodic nonfunctional gnashing, grinding, or clenching of teeth, unlike chewing movements of the mandible, which may lead to occlusal trauma [1]. The term "la bruxomanie" was used for the first time by Maria Pietkiewicz in 1907 [2].

Research shows that the most dangerous form of this pathology is night bruxism, which has a psychoemotional and occlusal origin $[3,4]$. If not treated, it leads to damage of the teeth, periodontium and oral mucosa, pathology of the muscles constituting the masticatory system, headache and cervical pain, temporomandibular, and hearing disorders [5]. Stress related disturbances, including depression and anxiety, are a real problem in a highly developed society. Clinical studies suggest that stress is the main reason for patients to seek medical advice (50-75\%) [6-8]. This is also confirmed by the large number of medicines used in order to treat stress related problems in western countries such as antidepressants, anxiolytics, and hypnotics, which decrease arterial blood pressure and the level of cholesterol [9]. Moreover, the number of patients seeking treatment because of temporomandibular disorders and oral parafunctions is increasing, which may confirm a correlation between these conditions and a growing number of chronic stressors in highly developed societies. This type of disorder can also be observed in younger people and it is more common in females [10-13]. It is generally accepted that chronic stressful situations and mental diseases conduct to the development of occlusal parafunctions and temporomandibular disorders without being the only cause. Additional reasons include interceptive occlusal contacts, malocclusions, traumas/microtraumas, hormone disorders, rheumatism, orthopedic problems, and masticatory system inflammations [14-16]. A rapid development of this disease at the turn of the 20th and 21st centuries induced the authors to attempt to find a cause of this process.

The aim of this paper is to show the correlation between chronic stress, development of civilization, and bruxism based on current literature.

\section{Materials and Methods}

Literature is available from PubMed, PubMed Central, and CINAHL databases that were published between 1955 and 
2014. Valuable original and review articles related to the terms bruxism, stress, occlusal parafunctions, temporomandibular disorders, psychology, anthropology, and sociology have been selected for this paper.

\section{Results}

3.1. Psychological Aspects of Bruxism. According to Selye [24], stress involves a biological strain of an organism, which is caused by various somatic and/or mental stimuli. These stimuli are called stressors. "Being under stress" means that a person is under an influence of unspecified stimuli, which are revealed by specific changes characterizing this situation. Stressors, regardless of their type, stimulate in an organism stereotypical, nonspecific, and complex adaptation reactions. This adaptation is controlled by hormonal and neurohormonal processes. A state of strain of an organism is called stress, and it can be divided into acute and chronic. Chronic stress belongs to the most destructive factors threatening a human organism [25].

Servan-Schreiber et al. [26-29] present the pathophysiology of stress in a different way. They report a so-called "emotional brain," which has a completely separate structure from the neocortex and it functions independently. This "brain" is located in the limbic system, so in the central part of the encephalon, and it consists of three main anatomical elements: the hippocampal gyrus, cingulate gyrus, and amygdala. These elements have a far less complicated structure than the neocortex; that is, they are not arranged in regular bundles of neurons, but the nerve cells are rather mixed here. The "emotional brain" controls vital emotions and reactions. Pathological chronic stress and emotional disorders result from functional disturbances of the "emotional brain," which most often are a consequence of traumas and/or family and professional life. All impressions concerning external environment are processed in the brain. The central nervous system is responsible for their assessment. Signals reach the limbic system and hypothalamus, where they trigger proper emotions and stimulate the sympathetic nervous system releasing adrenaline, which i.a. leads to faster breathing and heartbeat, a higher muscle tension, and an increased sugar level and blood pressure. Any external information which triggers such a response may be recognized as a stressor [30, 31]. Our ancestors usually manifested this analysed biological warning reaction in a form of motor activity. After surviving the danger, their bodies functioned normally again. A contemporary individual, living in a highly developed society, has been deprived of these reaction possibilities. The effects of suppressing emotions and motor activities burden the function of an organism resulting in several neuromuscular disorders [32].

Various pathological emotional experiences more and more often result in the development of a muscular parafunction/bruxism. This can be related to occlusion or can be caused entirely by psychological stimulation. It had been proved that compulsive, controlling, and aggressive persons are more vulnerable to develop bruxism [33]. This disorder involves unconscious teeth clenching and grinding, which leads to gradual damage of the dentition and periodontium, damage of the oral mucosa, increased tension and hypertrophy of masticatory muscles, chronic headaches and cervical pain, and abnormality of the temporomandibular joints as well as hearing problems [18-22]. The most important symptoms related to bruxism are presented in Table 1. Suggestions that teeth grinding is connected with malocclusions do not seem to be true. Dental patients (5-30\%) suffer from this type of disorders occurring in the temporomandibular joint, whereas $50-75 \%$ of society needs to be treated orthodontically, at least to a moderate degree [23]. Accordingly, this malocclusion is classified as peripheral factor influencing bruxism [2]. Bruxism is a parafunction in which the contraction of the temporal and masseter muscles is responsible for clenching of the dental arches, while the contraction of the pterygoid muscles is responsible for lateral movements, potentially affecting the temporomandibular joints [34]. The most destructive type of this disorder is sleep bruxism [35]. This condition is associated with a rhythmic activity of the masticatory muscles, characterized by a repeated contraction of the masticatory muscles. The highest activity is observed during the phase of sleep called REM (rapid eye movement sleep). In this phase, several parts of the encephalon, including the limbic system, are very active [36]. According to literature, average activity of muscles is several times more intensive in patients with bruxism than in patients showing no bruxism symptoms [36-38]. The intensity of contractions during sleep considerably exceeds a maximum patients' ability to clench their teeth when they are aware of it [39]. Based on the etiology, bruxism can be divided into awake, sleep, occlusion-dependent, psycho-dependent, and a mixed type depending both on the occlusion and psyche. Based on the mandible movements, bruxism is classified as centric, lateral eccentric, anterior eccentric, mixed eccentric, and extra eccentric [40].

A muscle, when passive, stays under constant tension resulting from the alpha neurons stimulation by the central stream of impulses. This tension does not lead to muscle fatigue. The main role in the tension coordination belongs to gamma neurons, which are controlled by higher centers and participate in the development of an abnormal muscle activity (Figure 1) [17]. Chronic stress and warning reactions triggered by it manifest themselves as functional deficiencies of the nervous-muscle system and are the main etiologic factors of psycho-dependent bruxism [41]. When these disturbances appear, attention is drawn by venting the accumulated tensions directly through the dental arches, by means of increased muscle activity, which may lead to headaches. This abnormal activity and increased tension are controlled by the limbic system and hypothalamus, stimulated by chronic stress, which are connected with the cortex. In this way, through the reticular formation of the brainstem occurs a correlation between stimulating awareness, vegetative activities, and affective emotional behavior along with the muscle tension. Central stimulations increase a segment reflex activity mainly over stimulation of gamma motor neurons. The increased reflex activity causes muscle tone, which may vary from a state of higher tension up to rigidity. The gamma loop is activated through the descending reticulospinal tract, which results in increased muscle tone. The possibility of 
TABLE 1: Possible symptoms of bruxism according to medical disciplines [18-23].

\begin{tabular}{ll}
\hline Branch of medicine & Symptoms observed \\
\hline Dentistry & $\begin{array}{l}\text { Clenching or grinding of the teeth while asleep (often noticed by sleeping partner); hypersensitivity of teeth to } \\
\text { hot, cold, sweet, and so forth; attrition; fractures of teeth; negative consequences in periodontium/gingival } \\
\text { recessions; loss of teeth; damages and cracks of fixed and removable dentures (especially dental ceramics); cheek } \\
\text { and tongue biting }\end{array}$ \\
\hline Otolaryngology & Ear sounds (tinnitus), ear aches (referred pain) with possible hearing loss, ear infections, apnea \\
\hline Neurology & $\begin{array}{l}\text { Constant, dull headache; pain in the temples; sleep disorders (insomnia); anxiety, stress, and depression; } \\
\text { dizziness; vertigo }\end{array}$ \\
\hline Ophthalmology & Hypersensitivity to light, pain in the eye or around the eye, difficulties in sight focus \\
\hline Physical Therapy & $\begin{array}{l}\text { Sore jaw muscles, facial pain or jaw pain, higher muscle tension, myofascial pain, temporomandibular joint } \\
\text { disorders (clicking), trismus, hand and arm tingling }\end{array}$ \\
\hline Others & Changes in facial appearance, eating disorders \\
\hline
\end{tabular}

an influence of the higher centers can lead to an abnormal increase of muscle tone, which explains the occurrence of higher muscle activity triggered by psychological stimuli [4244].

3.2. Social Aspects of Bruxism. According to Young [45], the rapid development of civilization is an apparent factor conducive to diseases, which do not pose a direct threat to human life. The author describes the changes in the dentition of native inhabitants of Australia, which occurred after contact with western culture. Aborigines' oral hygiene improved considerably, but changes of eating habits and consumption of a large amount of food with high sugar content as well as soft diet caused an unexpected increase of teeth crowding and dental caries. A change in lifestyle and diet prevented the dentition from severe attrition. Occlusal-muscular disorders were quite rare. Because of changes in nutritional habits, for example, softer diet at the expense of raw meat and vegetables, nowadays contemporary inhabitants of Australia use different and less muscle groups than the primitive tribes or the inhabitants in the 19th century. For this reason, contemporary inhabitants suffer from similar functional disorders of the stomatognathic system, regardless of their background. Watson [46] studied the changes in dentition of the inhabitants of north-west Mexico and showed the impact of diet and agricultural factors on the health of teeth tissue. The dentition of this group clearly shows that the development of civilization reduced the physiological wear-and-tear of the teeth, which followed the changes in nutrition. Moreover, the author suggests that psychological factors and a diet of the contemporary people inhabiting this region are causative factors of changes of a different type, that is, caries and noncaries defects.

The studies explicitly revealed that a new form of losing teeth must be connected with a different impact of contemporary environment on the stomatognathic system. Omnipresent chronic stressors, to which a human organism is subjected every day, lead indirectly to various disorders. The study of Bayar et al. [47] proves that occlusal parafunctions are closely connected with psychological disturbances of different degrees of severity, most of which are caused by an inability to accept everyday reality or by exaggeration of experiencing external stimuli. Bayar assumes that the etiopathogenesis of bruxism is complex; nevertheless, he indicates that the most important is the psychological factor, which is also confirmed by other authors [48, 49]. The studies of Bracha et al. [50] and Gungormus and Erciyas [51] distinguish from 3 many emotional disorders those which are accompanied by occluso-muscle disorders, that is, excessively experienced stress, depression, neurosis, phobias, personality disorders, anxiety, and paranoid states. These diseases are common in highly developed societies, in which surrounding environment directly leads to their occurrence. Chronic stress, lack of sleep, rest time, and activities are conducive to the development of psychoemotional disorders, vascular diseases, dermatological problems, gastric disturbances, and neuromuscular disorders [52-55]. Omnipresent chronic stressors in a contemporary society are called civilization stress [56]. Independent of mental disorders, availability and overuse of stupefying agents may result in an increase of parafunctional muscular activity. This problem was proved by Gomez et al. [57], whose study confirms a correlation between drug addiction and an increase of abnormal occlusomuscle function.

Manfredini et al. [58] show that significant factors in the development of occlusal parafunctions are malocclusions and abnormal bites. It should be stressed that an occlusal aspect most often connected with psychological disorders gives the picture of full-blown bruxism. In everyday clinical practice, patients who are diagnosed with occlusal problems often do not show symptoms characteristic of emotional disturbances. Only after taking the patient's medical history are revealed problems often related to the family and/or professional life. It should be emphasized that a properly conducted medical interview as well as a physical examination is an important part of therapy of the temporomandibular disorders.

A change of profile of health threats as well as a longer lifespan in contemporary societies caused dissemination of diseases and treatment methods, which were very rare or even did not exist in the past. An example of such change is the orthodontic treatment, whose rapid development took place in the second part of the 20th century. Chu et al. [59] confirm this thesis in their study, which is based on a group of 240 students, $41 \%$ of whom undergo/underwent 


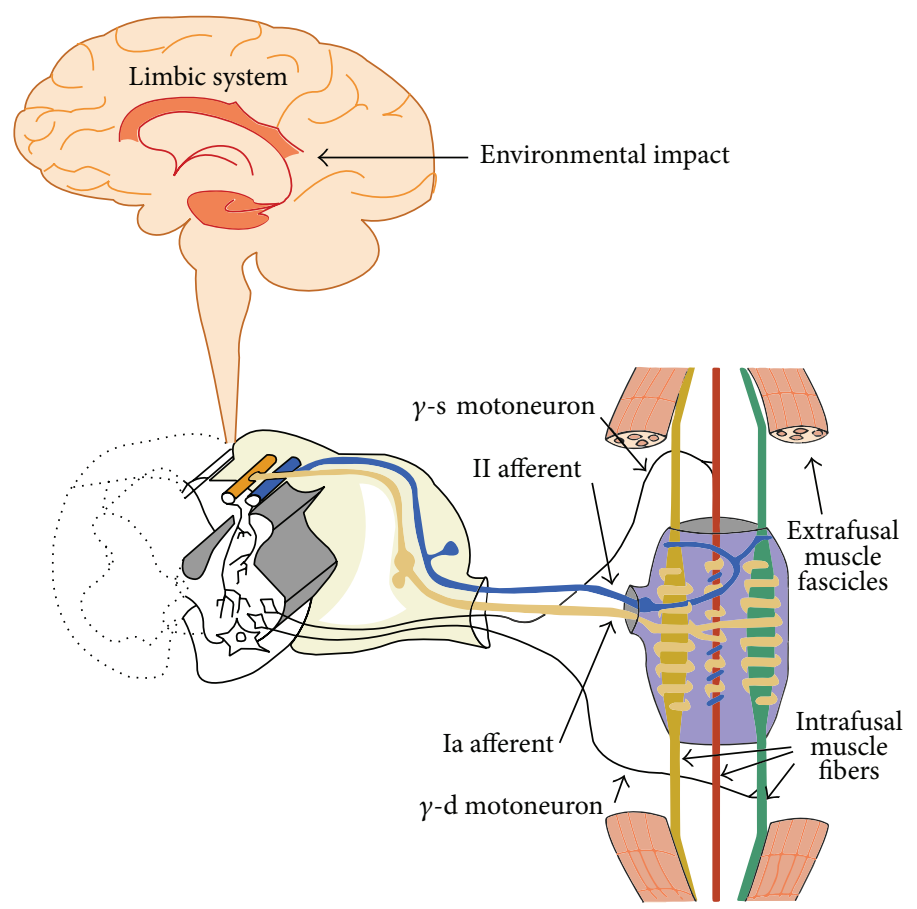

FIGURE 1: Schematic diagram of the gamma loop, which is permanently stimulated by external impulses in a group of people affected by chronic stress [17].

orthodontic treatment. Nonetheless, occluso-muscle parafunctions belong to a group of disorders, which affect an increasing part of a society. Frequently, these parafunctions are a cause of dental treatment failure. Kinsel and Lin [60] studied the prosthetic complications in 152 patients with implant borne fixed dental prostheses and proved seven times higher odds in bruxers.

Other studies reveal that a frequency of occluso-muscle disorders also depends on ethnic background. Hicks et al. [61] conducted studies concerning the frequency of bruxism among American students of different backgrounds. The results showed higher bruxism prevalence in students of Asian origin, an average among European and Latin-American group and the lowest in the Afro-American group. Several authors proved that psycho-dependent occlusal parafunctions more and more often concern children under 10 years [62-64]. These studies reveal that occluso-muscle disorders affect people of different ages. However, bruxism is more common in females [2].

\section{Discussion}

The etiology of bruxism is multifactorial. Occlusion abnormalities, chronic stress, and mental disorders are responsible for this condition. It should be highlighted that there is a tendency of more frequent occurrence of oral parafunctions in highly developed societies. Thus, it seems that the occlusal aspect in the development of bruxism is of minor importance. This is confirmed by studies in which bruxism is observed in patients with implant borne restorations, among them there is no impulsation from the periodontium [65]. Symptoms of bruxism may be unnoticeable for a longer period. Only after having experienced a nagging pain does a patient start to seek medical help. Patients often consult doctors of different specialties, especially neurologists or ophthalmologists, but also ENT specialists, since one of the symptoms of severe bruxism can be a sleep apnea, resulting in a long-term state of chronic fatigue and increasing stress related to "not keeping up" with projects. Bruxism functions as a kind of perpetual motion machine, as intensifying symptoms resulting from the abnormal functioning of an organism increase a feeling of being stressed, and in consequence leads to an increased muscle tone and teeth grinding $[66,67]$. In its stage, this problem is often ignored by patients, which has serious consequences in the form of destruction of the dentition and severe abnormalities of muscles and joints. In this phase, the condition requires at least two-phased prosthetic treatment. It also calls for multidisciplinary treatment, in which specialists like a dentist, psychiatrist, neurologist, psychologist, physiotherapist, and a dental technician should participate. Worldwide discussions and studies of scientists resulted in recognizing sleep bruxism as a disorder, which was then included in the International Classification of Sleep Disorders in 2005 [67].

\section{Conclusions}

On the basis of the data collected by the authors based on current literature it can be stated that the prevalence of bruxism depends on the development of civilization and the modern lifestyle. In this way the psychological aspect of occlusomuscle disorders becomes more significant. Contemporary environment is full of incessant stress threats and thus 
dangerous to our health and life. In recent years, the number of patients suffering from bruxism has increased significantly. For this reason doctors should pay more attention to this parafunction in order to diagnose it at an early stage.

\section{Conflict of Interests}

The authors declare that there is no conflict of interests regarding the publication of this paper.

\section{Acknowledgment}

The authors would like to thank Mr. Michal Kowaliszyn, MSc, for preparing the diagram.

\section{References}

[1] The Academy of Prosthodontics, "The glossary of prosthodontics terms 8th edition," Journal of Prosthetic Dentistry, vol. 94, no. 1, pp. 10-29, 2005.

[2] S. Shetty, V. Pitti, C. L. S. Babu, G. P. S. Kumar, and B. C. Deepthi, "Bruxism: a literature review," Journal of Indian Prosthodontist Society, vol. 10, no. 3, pp. 141-148, 2010.

[3] A. de Laat and G. M. Macaluso, "Sleep bruxism as a motor disorder," Movement Disorders, vol. 17, no. 2, pp. S67-S69, 2002.

[4] G. J. Lavigne, S. Khoury, S. Abe, T. Yamaguchi, and K. Raphael, "Bruxism physiology and pathology: an overview for clinicians," Journal of Oral Rehabilitation, vol. 35, no. 7, pp. 476-494, 2008.

[5] D. Manfredini, N. Landi, F. Fantoni, M. Segù, and M. Bosco, "Anxiety symptoms in clinically diagnosed bruxers," Journal of Oral Rehabilitation, vol. 32, no. 8, pp. 584-588, 2005.

[6] N. A. Cummings and G. R. VandenBos, "The twenty years Kaiser-Permanente experience with psychotherapy and medical utilization: implications for national health policy and national health insurance," Health Policy Quarterly, vol. 1, no. 2, pp. 159$175,1981$.

[7] L. G. Kessler, P. D. Cleary, and J. D. Burke Jr., "Psychiatric disorders in primary care. Results of a follow-up study," Archives of General Psychiatry, vol. 42, no. 6, pp. 583-587, 1985.

[8] B. H. McFarland, D. K. Freeborn, J. P. Mullooly, and C. R. Pope, "Utilization patterns among long-term enrollees in a prepaid group practice health maintenance organization," Medical Care, vol. 23, no. 11, pp. 1221-1233, 1985.

[9] S. Blanchard, “Top ten drugs of 2001," Pharmacy Times, vol. 68, no. 4, pp. 10-15, 2002.

[10] A. Anastassaki Köhler, A. Hugoson, and T. Magnusson, "Prevalence of symptoms indicative of temporomandibular disorders in adults: cross-sectional epidemiological investigations covering two decades," Acta Odontologica Scandinavica, vol. 70, no. 3, pp. 213-223, 2012.

[11] F. Liu and A. Steinkeler, "Epidemiology, diagnosis, and treatment of temporomandibular disorders," Dental Clinics of North America, vol. 57, no. 3, pp. 465-479, 2013.

[12] A. A. Köhler, A. Hugoson, and T. Magnusson, "Clinical signs indicative of temporomandibular disorders in adults: time trends and associated factors," Swedish Dental Journal, vol. 37, no. 1, pp. 1-11, 2013.

[13] M. Schmid-Schwap, M. Bristela, M. Kundi, and E. Piehslinger, "Sex-specific differences in patients with temporomandibular disorders," Journal of Orofacial Pain, vol. 27, no. 1, pp. 42-50, 2013.
[14] M. K. A. van Selms, F. Lobbezoo, C. M. Visscher, and M. Naeije, "Myofascial temporomandibular disorder pain, parafunctions and psychological stress," Journal of Oral Rehabilitation, vol. 35, no. 1, pp. 45-52, 2008.

[15] C. Di Paolo, G. D. Costanzo, F. Panti et al., "Epidemiological analysis on 2375 patients with TMJ disorders: basic statistical aspects," Annali di Stomatologia, vol. 4, no. 1, pp. 161-169, 2013.

[16] A. Safari, Z. Jowkar, and M. Farzin, "Evaluation of the relationship between bruxism and premature occlusal contacts," Journal of Contemporary Dental Practice, vol. 14, no. 4, pp. 616-621, 2013.

[17] R. Granit, "The gamma $\gamma$ loop in the mediation of muscle tone," Clinical Pharmacology and Therapeutics, vol. 5, no. 2, pp. 837847, 1964.

[18] Y. Hasegawa, G. Lavigne, P. Rompré, T. Kato, M. Urade, and N. Huynh, "Is there a first night effect on sleep bruxism? A sleep laboratory study," Journal of Clinical Sleep Medicine, vol. 9, no. 11, pp. 1139-1145, 2013.

[19] S. Abe, J. Gagnon, J. Y. Montplaisir et al., "Sleep bruxism and oromandibular myoclonus in rapid eye movement sleep behavior disorder: a preliminary report," Sleep Medicine, vol. 14, no. 10, pp. 1024-1030, 2013.

[20] S. S. de Rossi, I. Stern, and T. P. Sollecito, "Disorders of the masticatory muscles," Dental Clinics of North America, vol. 57, no. 3, pp. 449-464, 2013.

[21] G. Fernandes, A. L. Franco, D. A. Gonçalves, J. G. Speciali, M. E. Bigal, and C. M. Camparis, "Temporomandibular disorders, sleep bruxism, and primary headaches are mutually associated," Journal of Orofacial Pain, vol. 27, no. 1, pp. 14-20, 2013.

[22] K. Walczyńska-Dragon and S. Baron, "The biomechanical and functional relationship between temporomandibular dysfunction and cervical spine pain," Acta of Bioengineering and Biomechanics, vol. 13, no. 4, pp. 93-99, 2011.

[23] J. A. McNamara Jr., D. A. Seligman, and J. P. Okeson, "Occlusion, Orthodontic treatment, and temporomandibular disorders: a review.", Journal of orofacial pain, vol. 9, no. 1, pp. 73-90, 1995.

[24] H. Selye, "Stress and disease," Science, vol. 122, no. 3171, pp. 625631, 1955.

[25] R. Grossarth-Maticek and H. J. Eysenck, "Self-regulation and mortality from cancer, coronary heart disease, and other causes: a prospective study," Personality and Individual Differences, vol. 19, no. 6, pp. 781-795, 1995.

[26] D. Servan-Schreiber, W. M. Perlstein, J. D. Cohen, and M. Mintun, "Selective pharmacological activation of limbic structures in human volunteers: a positron emission tomography study," Journal of Neuropsychiatry and Clinical Neurosciences, vol. 10, no. 2, pp. 148-159, 1998.

[27] D. Servan-Schreiber, R. Kolb, and G. Tabas, “The somatizing patient," Primary Care, vol. 26, no. 2, pp. 225-242, 1999.

[28] D. Servan-Schreiber, N. R. Kolb, and G. Tabas, "Somatizing patients: part I. Practical diagnosis," American Family Physician, vol. 61, no. 4, pp. 1073-1078, 2000.

[29] D. Servan-Schreiber, G. Tabas, and N. R. Kolb, "Somatizing patients: part II. Practical management," The American Family Physician, vol. 61, no. 5, pp. 1423-1432, 2000.

[30] H. Yang, J. J. Durocher, R. A. Larson, J. P. DellaValla, and J. R. Carter, "Total sleep deprivation alters cardiovascular reactivity to acute stressors in humans," Journal of Applied Physiology, vol. 113 , no. 6, pp. 903-908, 2012.

[31] J. L. Boone and J. P. Anthony, "Evaluating the impact of stress on systemic disease: the MOST protocol in primary care," The 
Journal of the American Osteopathic Association, vol. 103, no. 5, pp. 239-246, 2003.

[32] R. J. Marker, J. L. Stephenson, B. M. Kluger, D. Curran-Everett, and K. S. Maluf, "Modulation of intracortical inhibition in response to acute psychosocial stress is impaired among individuals with chronic neck pain," Journal of Psychosomatic Research, vol. 76, no. 3, pp. 249-256, 2014.

[33] T. Takemura, T. Takahashi, M. Fukuda et al., "A psychological study on patients with masticatory muscle disorder and sleep bruxism," The Journal of Cranio mandibular and Sleep Practice, vol. 24, no. 3, pp. 191-196, 2006.

[34] H. A. Israel, B. Diamond, F. Saed-Nejad, and A. Ratcliffe, "The relationship between parafunctional masticatory activity and arthroscopically diagnosed temporomandibular joint pathology," Journal of Oral and Maxillofacial Surgery, vol. 57, no. 9, pp. 1034-1039, 1999.

[35] M. Giraki, C. Schneider, R. Schäfer et al., "Correlation between stress, stress-coping and current sleep bruxism," Head and Face Medicine, vol. 6, no. 1, article 2, pp. 1-8, 2010.

[36] T. Kato, Y. Masuda, A. Yoshida, and T. Morimoto, "Masseter EMG activity during sleep and sleep bruxism," Archives Italiennes de Biologie, vol. 149, no. 4, pp. 478-491, 2011.

[37] S. Yoshizawa, T. Suganuma, M. Takaba et al., "Phasic jaw motor episodes in healthy subjects with or without clinical signs and symptoms of sleep bruxism: a pilot study," Sleep and Breathing, vol. 18, no. 1, pp. 187-193, 2014.

[38] C. F. Amorim, L. C. Giannasi, L. M. A. Ferreira et al., "Behavior analysis of electromyographic activity of the masseter muscle in sleep bruxers," Journal of Bodywork and Movement Therapies, vol. 14, no. 3, pp. 234-238, 2010.

[39] T. Kampe, T. Tagdae, G. Bader, G. Edman, and S. Karlsson, "Reported symptoms and clinical findings in a group of subjects with longstanding bruxing behaviour," Journal of Oral Rehabilitation, vol. 24, no. 8, pp. 581-587, 1997.

[40] F. Lobbezoo, J. Ahlberg, A. G. Glaros et al., "Bruxism defined and graded: an international consensus," Journal of Oral Rehabilitation, vol. 40, no. 1, pp. 2-4, 2013.

[41] H. Abekura, M. Tsuboi, T. Okura, K. Kagawa, S. Sadamori, and Y. Akagawa, "Association between sleep bruxism and stress sensitivity in an experimental psychological stress task," Biomedical Research, vol. 32, no. 6, pp. 395-399, 2011.

[42] R. B. Leistad, T. Sand, R. H. Westgaard, K. B. Nilsen, and L. J. Stovner, "Stress-induced pain and muscle activity in patients with migraine and tension-type headache," Cephalalgia, vol. 26, no. 1, pp. 64-73, 2006.

[43] R. de Leeuw, J. E. Schmidt, and C. R. Carlson, "Traumatic stressors and post-traumatic stress disorder symptoms in headache patients," Headache, vol. 45, no. 10, pp. 1365-1374, 2005.

[44] A. G. Glaros, K. Williams, and L. Lausten, "The role of parafunctions, emotions and stress in predicting facial pain," Journal of the American Dental Association, vol. 136, no. 4, pp. 451-458, 2005.

[45] W. G. Young, "Anthropology, tooth wear, and occlusion ab origine," Journal of Dental Research, vol. 77, no. 11, pp. 1860-1863, 1998.

[46] J. T. Watson, "Changes in food processing and occlusal dental wear during the early agricultural period in Northwest Mexico," American Journal of Physical Anthropology, vol. 135, no. 1, pp. 92-99, 2008.

[47] G. R. Bayar, R. Tutuncu, and C. Acikel, "Psychopathological profile of patients with different forms of bruxism," Clinical Oral Investigations, vol. 16, no. 1, pp. 305-311, 2012.
[48] D. Manfredini and F. Lobbezoo, "Role of psychosocial factors in the etiology of bruxism," Journal of Orofacial Pain, vol. 23, no. 2, pp. 153-166, 2009.

[49] E. Katayoun, F. Sima, V. Naser, and D. Anahita, "Study of the relationship of psychosocial disorders to bruxism in adolescents," Journal of Indian Society of Pedodontics and Preventive Dentistry, vol. 26, supplement 3, no. 7, pp. S91-S97, 2008.

[50] H. S. Bracha, T. C. Ralston, A. E. Williams, J. M. Yamashita, and A. S. Bracha, "The clenching-grinding spectrum and fear circuitry disorders: clinical insights from the neuroscience/paleoanthropology interface," CNS Spectrums, vol. 10, no. 4, pp. 311318, 2005.

[51] Z. Gungormus and K. Erciyas, "Evaluation of the relationship between anxiety and depression and bruxism," Journal of International Medical Research, vol. 37, no. 2, pp. 547-550, 2009.

[52] A. I. Alterman, J. S. Cacciola, M. A. Ivey et al., "Relationship of mental health and illness in substance abuse patients," Personality and Individual Differences, vol. 49, no. 8, pp. 880-884, 2010.

[53] X. Lv, D. Han, L. Xi, and L. Zhang, "Psychological aspects of female patients with moderate-to-severe persistent allergic rhinitis," ORL, vol. 72, no. 5, pp. 235-241, 2010.

[54] B. van Houdenhove, S. Kempke, and P. Luyten, "Psychiatric aspects of chronic fatigue syndrome and fibromyalgia," Current Psychiatry Reports, vol. 12, no. 3, pp. 208-214, 2010.

[55] M. Bellini, I. Marini, V. Checchi, G. A. Pelliccioni, and M. R. Gatto, "Self-assessed bruxism and phobic symptomatology," Minerva Stomatologica, vol. 60, no. 3, pp. 93-103, 2011.

[56] K. Simon, "Civilization stress, cardiovascular risk, evidence based medicine, guideline," Orvosi Hetilap, vol. 150, no. 19, pp. 895-902, 2009.

[57] E. M. Gómez, M. P. Areso, M. T. Giralt, B. Sainz, and P. GarcíaVallejo, "Effects of dopaminergic drugs, occlusal disharmonies, and chronic stress on non-functional masticatory activity in the rat, assessed by incisal attrition," Journal of Dental Research, vol. 77, no. 6, pp. 1454-1464, 1998.

[58] D. Manfredini, N. Landi, M. Romagnoli, and M. Bosco, "Psychic and occlusal factors in bruxers," Australian Dental Journal, vol. 49, no. 2, pp. 84-89, 2004.

[59] C. H. Chu, B. H. B. Choy, and E. C. M. Lo, "Occlusion and orthodontic treatment demand among Chinese young adults in Hong Kong," Oral Health \& Preventive Dentistry, vol. 7, no. 1, pp. 83-91, 2009.

[60] R. P. Kinsel and D. Lin, "Retrospective analysis of porcelain failures of metal ceramic crowns and fixed partial dentures supported by 729 implants in 152 patients: Patient-specific and implant-specific predictors of ceramic failure," Journal of Prosthetic Dentistry, vol. 101, no. 6, pp. 388-394, 2009.

[61] R. A. Hicks, K. Lucero-Gorman, J. Bautista, and G. J. Hicks, "Ethnicity and bruxism," Perceptual and Motor Skills, vol. 88, no. 1, pp. 240-241, 1999.

[62] J. M. Serra-Negra, M. L. Ramos-Jorge, C. E. Flores-Mendoza, S. M. Paiva, and I. A. Pordeus, "Influence of psychosocial factors on the development of sleep bruxism among children," International Journal of Paediatric Dentistry, vol. 19, no. 5, pp. 309-317, 2009.

[63] M. Simões-Zenari and M. L. Bitar, "Factors associated to bruxism in children from 4-6 years," Pro-Fono, vol. 22, no. 4, pp. 465-472, 2010.

[64] S. E. Widmalm, S. M. Gunn, R. L. Christiansen, and L. M. Hawley, "Association between CMD signs and symptoms, oral 
parafunctions, race and sex, in 4-6-year-old African-American and Caucasian children," Journal of Oral Rehabilitation, vol. 22, no. 2, pp. 95-100, 1995.

[65] H. R. Sarmento, R. V. F. Dantas, T. Pereira-Cenci, and F. Faot, "Elements of implant-supported rehabilitation planning in patients with bruxism," Journal of Craniofacial Surgery, vol. 23, no. 6, pp. 1905-1909, 2012.

[66] A. Oksenberg and E. Arons, "Sleep bruxism related to obstructive sleep apnea: the effect of continuous positive airway pressure," Sleep Medicine, vol. 3, no. 6, pp. 513-515, 2002.

[67] American Academy of Sleep Medicine (AASM), International Classification of Sleep Disorders, American Academy of Sleep Medicine (AASM), Westchester, Ill, USA, 2nd edition, 2005. 


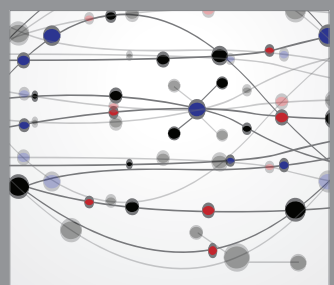

The Scientific World Journal
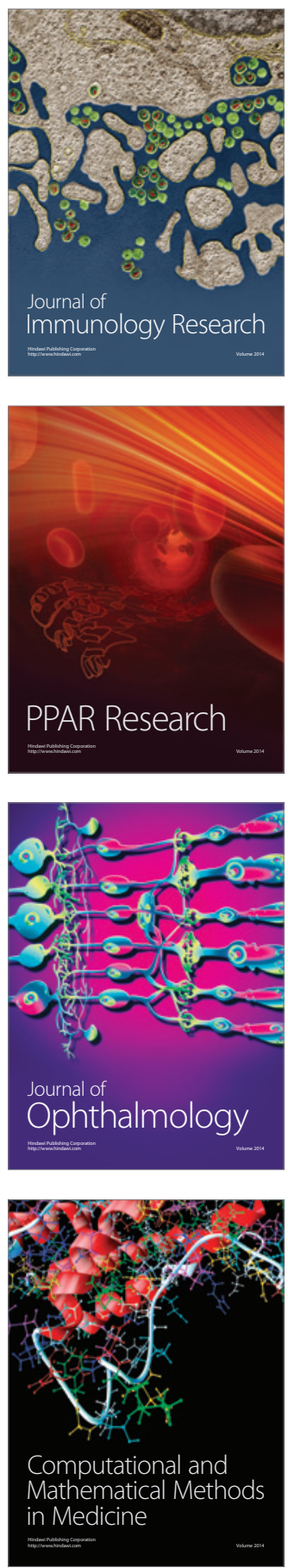

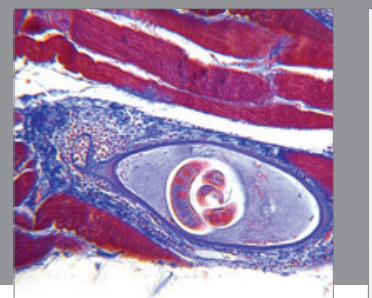

Gastroenterology

Research and Practice
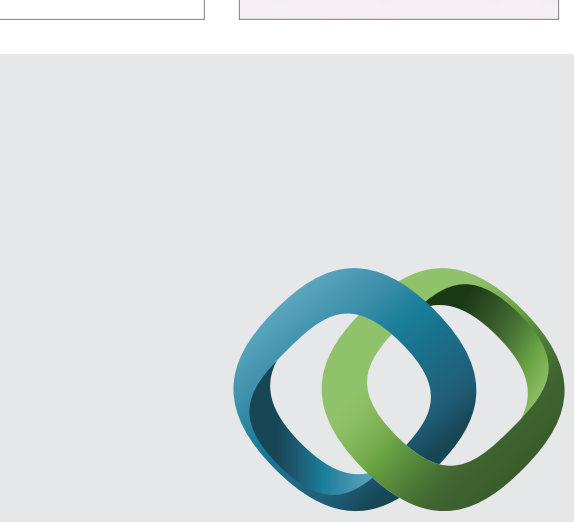

\section{Hindawi}

Submit your manuscripts at

http://www.hindawi.com
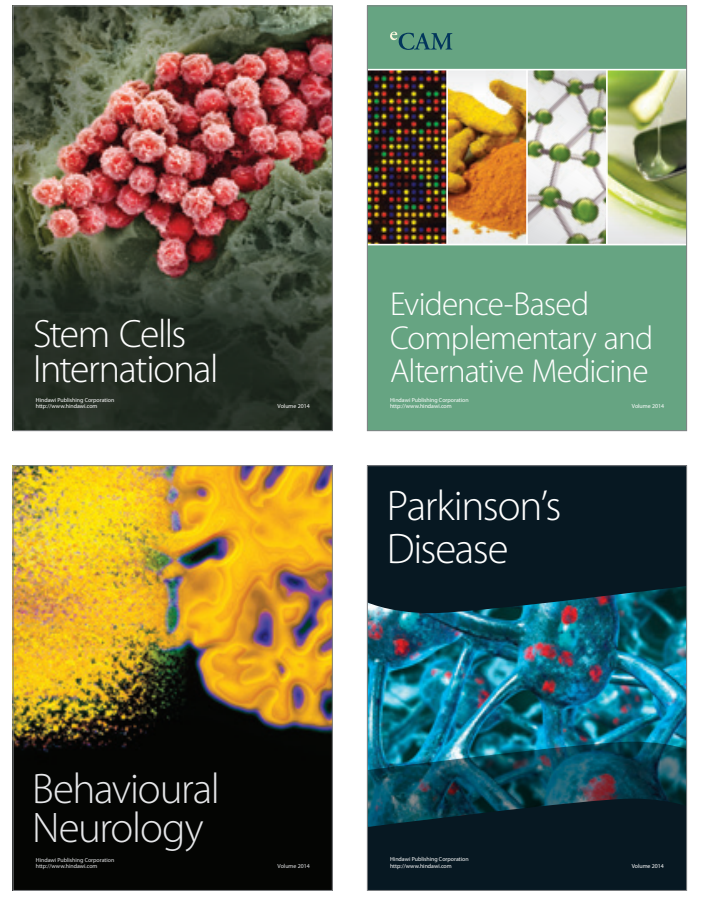
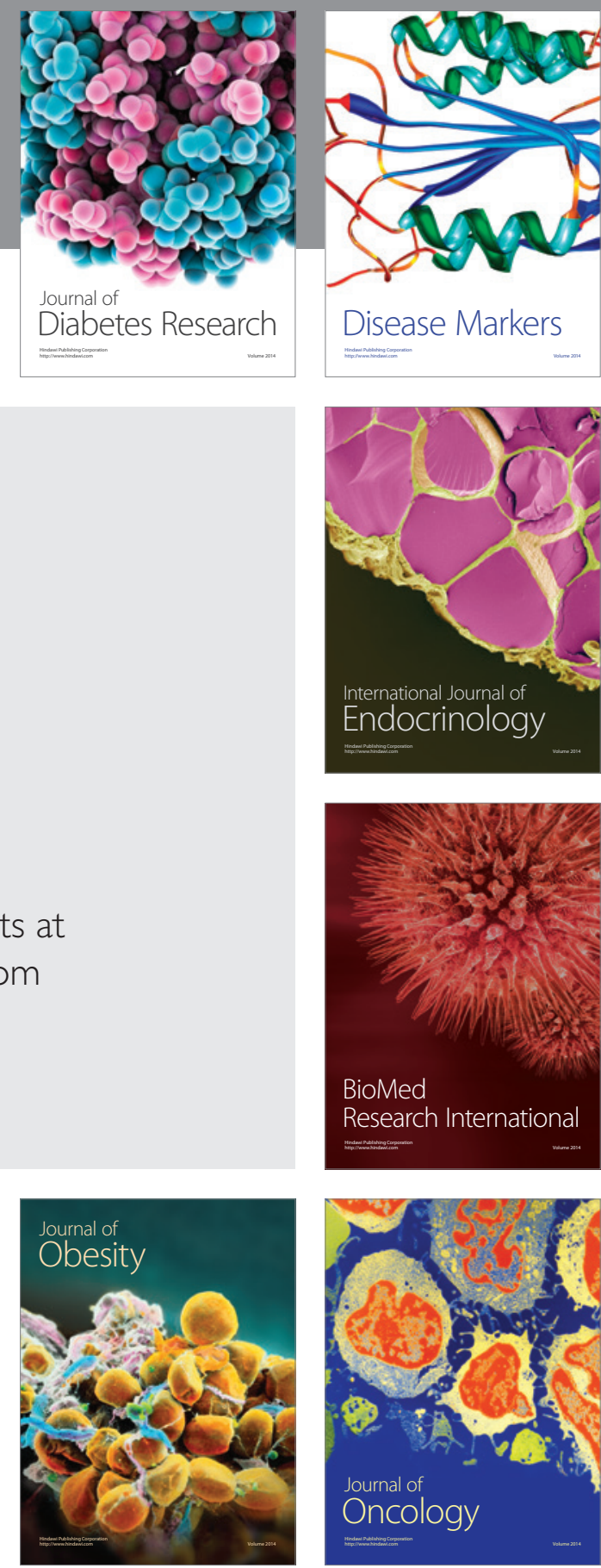

Disease Markers
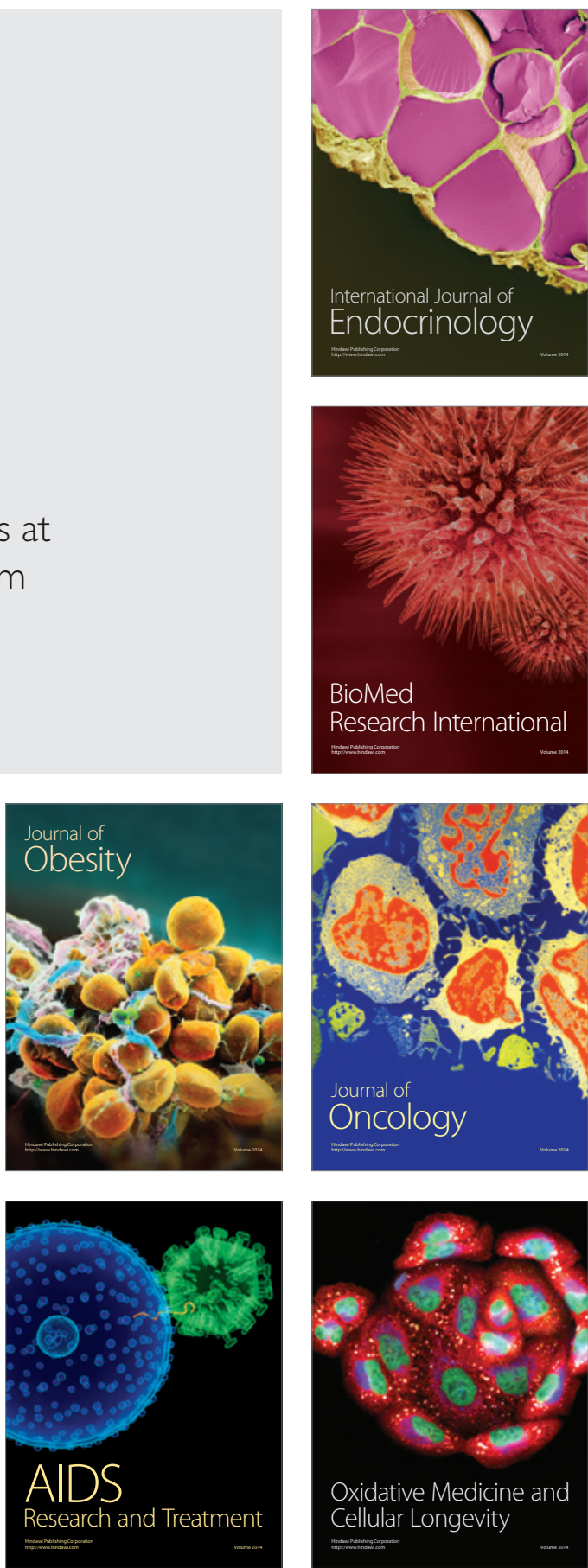